\title{
FRONTIERE ȘI CONTACTE. STUDII CULTURALE
}

\section{BORDERS AND CONTACTS. CULTURAL STUDIES}

\author{
Mihaela ALBU \\ Uniunea Scriitorilor din România/ Writers' Union of Romania \\ Uniunea Ziariștilor Profesioniști/ The Union of Professional Journalists \\ e-mail: malbu47@gmail.com
}

\begin{abstract}
The volume Borders and Contacts. Local, Regional and Global Phenomena, coordinated by Carmen Darabus and Camelia Zabava, brings together 28 papers presented by different scholars (from Romania, Bulgaria, Italy, Poland, Ukraine, the Northern Macedonia, Lithuania, and Sweden) in a panel organized at Veliko Tarnovo, Bulgaria, in June 22nd 2019. The volume is structured in three chapters: linguistics, literature and cultural studies. All the papers, having different subjects, are subordinated to the maine topic and try to demonstrate that the borders separate people, but the culture unites them.
\end{abstract}

Keywords: borders; local; regional; linguistics; literature; culture.

La începutul anului 2020, apare la Editura Aius din Craiova, în foarte bune condiții grafice, lucrarea colectivă, coordonată de doamnele Carmen Dărăbuș și Camelia Zăbavă, Frontiere și contacte. Fenomene locale, regionale și globale (364 p.).

După cum se arată și în Notă asupra ediției, volumul „,cuprinde lucrările mesei rotunde internaționale Frontiere și contacte. Fenomene locale, regionale și globale, care a avut loc în orașul Veliko Tărnovo, Bulgaria, în 22 iunie 2019, în cadrul Proiectului cu numărul 59/21.01. 2018, derulat sub egida Institutului Limbii Române din București, a Universitătilor „Sf. Kliment Ohridski” din Sofia, „Sf. Chiril și Metodiu” din VelikoTârnovo, a Universității Tehnice din Cluj-Napoca, Centrul Universitar Nord Baia Mare și a Asociației Culturale Internaționale Carmina Balcanica din Craiova" (Dărăbuș, Zăbavă, 2020: 9).

$\mathrm{Au}$ participat cu remarcabile contribuții cercetători și cadre didactice din România, Bulgaria, Italia, Polonia, Ucraina, Macedonia de Nord, Lituania și Suedia, iar comunicările mesei rotunde s-au derulat pe trei secțiuni: Limbăa, Literatură și Studii culturale și de istorie a mentalităților. Această organizare se regăsește și în volumul conferinței, care este structurat, la rândul lui în trei capitole: Studii de limbă, Studii de literatură și Studii culturale și de istorie a mentalitătilor. 
Prima parte, Studii de limbă (pp. 17-110) cuprinde o serie de materiale care acoperă o paletă largă a lingvisticii, purtând semnătura unor cercetători din Italia, Ucraina, Bulgaria, Macedonia de Nord și România: Davide Astori - De la guerre et de la paix, de Méduse, des Cyclopes et des Phéaciens. L'art de la distance, entre 'frontière' et 'contact', pour une grammaire de la relation (et de la coexistence), Serghii Luchanyn Observații asupra ediților lui Mihai Eminescu în limba ucraineană: particularitățile prefețelor, ale notelor și ale traducerilor, Silvia Mihăilescu, Boryana Emiliyanova - Uniunea lingvistică balcanică. Limbile bulgară și română în context balcanic, Constantin-Ioan Mladin - Limba română față în față cu globalizarea. De la limbajul de lemn la limbajul corporatist, Mihaela Moraru - Aspecte diacronice și sincronice ale traductologiei în România, Călin Florin Alexandru Popeț - Colivie cu sticleți pe cap. Interferențe semantice și efecte metaforice la nivelul unor frazeologisme din română și franceză , Elena-Camelia Zăbavă - Dincolo și dincoace de frontiere. Lingviști români în exil.

Dintre aceste studii, ne-a atras atenția în mod deosebit, pentru tematica abordată în special, articolul semnat de Camelia Zăbavă, Dincolo şi dincoace de frontiere. Lingviști români în exil. Autoarea aduce în discuție un subiect aflat la începutul cercetării astăzi, activitatea lingviștilor din exil, subliniind totodată necesitatea recuperării, alături de literatură, și a contribuțiilor lingvistice scrise peste graniță:

„Scrierile de lingvistică din exil se cer recuperate, alături de toată creația românească din afara granițelor. [...] În ultimul timp se observă un viu interes al cercetătorilor şi pentru gândirea lingvistică românească de dincolo de hotare [...] Prin această recuperare am putea spune că lingvistica românească din exil se întoarce acasă, trecând înapoi frontiera care nu mai este o graniță acum" (Zăbavă, 2020: 109).

Studii de literatură (pp. 113-216), cea de-a doua parte a volumului, reunește contribuții care au ca punct comun noțiunea de „frontieră”, fie că se referă la cea dintre real și imaginar, fie la cea geopolitică : Teodora Boboc Repere mitologice și simbolice în opera lui Mircea Eliade (pe baza romanului Șarpele), Marina Cap-Bun - Literature and Geopolitics in the Late Nineteenth Century: Ion Luca Caragiale and Aleko Konstantinov, Carmen Dărăbuș - Jean Bart, Europolis - un porto-franco al conviețuirii multiculturale, Magdalena Filary - Receptarea lui Mircea Eliade dincolo de frontierele României. Studiu de caz: Polonia, Delia Muntean - Momente în evoluția liricii românești din Voivodina, Alina Maria Nechita - Paula sau valențele literare ale confesiunii, Felix Nicolau - Moartea clinică a Canonului. Super-canonul candidează la tron, Ioana Slavcheva - Aspecte ale 
spațiului în câteva romane antitotalitariste românești din anii 60-70 ai secolului al XX-lea.

Foarte interesant, având în vedere puținele informații pe care le avem referitoare la cunoaștarea literaturii noastre în Polonia, este articolul Magdalenei Filary, intitulat Receptarea lui Mircea Eliade dincolo de frontierele României. Studiu de caz: Polonia. Aici, autoarea realizează o trecere în revistă a principalelor puncte de receptare de către exegeții polonezi a operei lui Mircea Eliade: Andrzej Kijowski, Zbigniew Benedyktynowicz, Wiktor Stoczkowski, Artur Rega, Stanisław Tokarski, Tadeusz Margul, Józef Borgosz. Concluzia care se desprinde din analizele criticilor literari, antropologilor și filozofilor polonezi asupra scrierilor lui Eliade, arată autoarea, se referă la faptul că receptarea operei lui Mircea Eliade în Polonia ,are în centru ambivalenţa metodologică determinată de cei doi poli: fenomenologic şi istoric" (Filary, 2020: 170).

Ultima secțiune, Studii culturale și de istorie a mentalităților (pp. 219-253), propune o serie de articole care tratează subiecte actuale ale culturii române, cum ar fi: aspecte ale exilului cultural românesc și necesitatea recuperării, probleme de etnografie surprinse de o parte și de alta a Dunării, interculturalitatea în literatură și în arta teatrală: Mihaela Albu Dincolo și dincoace de frontiere. Exilul românesc (Particularități culturale. Recuperări necesare), Ionela Carmen Banța - Religious, Cultural and Linguistic Romanian Identity at the Vatican Radio Station, Gabriela Boagiu Troițe românești pe ambele maluri ale Dunării, Ioana Bud - Le multiculturalisme et le défi de la traduction, Carmen Dărăbuș - Религията 8 румънската литература в началото на XX-и век, Ovidiu Ivancu - From Vlad Tुepeş to Count Dracula. A Challenging Relation between History and Myth, Ștefan Mariș - Fundamentalismul religios în era globalizării, Iolanda Mănescu - Un fenomen intercultural. Teatrul Național din Craiova dincolo de frontiere, Gabriela Motoi - Euro-optimism and Euroscepticism in Romania and Bulgaria, between 2007 and 2018, Daniela Sitar-Tăut Românişti slovaci. Studii și sinteze, Mihaela Suciu - Păcală, Djuha și Juha un personaj, trei culturi, Ligia Tomoiagă - Western and Eastern Fairy-Tales: Differences in Gender Roles.

Semnalăm aici articolul Iolandei Mănescu, Un fenomen intercultural. Teatrul Național din Craiova dincolo de frontiere, care prezintă activitatea de referință a teatrului craiovean în ultimul deceniu al mileniului trecut, recunoașterea sa internațională, Festivalul Internațional „Shakespeare” de la Craiova şi locul acestuia în rețeaua europeană a festivalurilor dedicate marelui dramaturg, autoarea accentuând ideea că ,arta și cultura, în special teatrul, nu cunosc frontiere și că, din acest punct de vedere, începutul celui de-al doilea mileniu stă sub semnul unității în diversitate" (Mănescu, 2020: 299). 
Un alt articol care atrage atenția este Româniști slovaci. Studii și sinteze, semnat de Daniela Sitar-Tăut. Autoarea prezintă pentru început un scurt istoric al relațiilor culturale româno-slovace, ca apoi interesul să se focuseze pe trei volume semnate de trei cunoscuți cercetători româniști: Libuša Vajdova, Receptarea culturii române în Slovacia (1890-1990), Jana Páleníková, Romanul românesc interbelic (teorii și realitate) și Peter Kopecký, Din mozaicul relațiilor culturale româno-slovace in secolul al XX-lea. Pe bună dreptate, Daniela Sitar-Tăut subliniază că „,cele trei volume constituie tot atâtea faţete ale receptării culturii, literaturii şi istoriei noastre în perimetrul slovac (cehoslovac)" (Star-Tăut, 2020: 325).

Putem concluziona că toate lucrările volumului Frontiere și contacte. Fenomene locale, regionale și globale, diferite ca subiecte și abordare, se subsumează unei aceleiași teme generale, bazate pe cele două axe, aflate în opoziție (aparentă): frontierele, care despart, din punct de vedere teoretic, dar care pot fi trecute prin contactele inter-umane, prin relațiile care se stabilesc în special în plan cultural. Și astfel, așa cum subliniază autoarele în Cuvântul inainte, dacă

„din punct de vedere politic, frontierele geografice sunt uneori granițe de netrecut; cultural însă, chiar dacă există bariere, ele pot fi depășite mult mai uşor şi prin aceasta tezaurul spiritual al omenirii se îmbogătește" (Dărăbuș, Zăbavă, 2020: 13).

\section{Referințe:}

Dărăbuş, C., Zăbavă, C. (2020). Frontiere și contacte. Fenomene locale, regionale și globale/ Borders and Contacts. Local, Regional and Global Phenomena. Craiova: Editura Aius. 